\title{
O ódio como excitação e o massacre vertical do outro ${ }^{1}$
}

\author{
Vera Regina J.R.M.Fonseca ${ }^{2}$ \\ "As a cyberobject, Trump gets held in mind in a timeless present \\ devoid of consequence in which all that matters is the capacity to \\ infinitely reproduce feelings of triumph and hate" (Essig, 2017)
}

\section{Resumo}

Dois exemplos clínicos são apresentado; um no qual o ódio e sadismo, tais como descritos por Klein, ilustram o componente de crueldade e inveja como parte das relações de objeto. Considera-se que a tolerância a tais sentimentos pode abrir caminho para o amor e consideração. O segundo exemplo diz respeito a um menino na puberdade que, com poucos habilidades sociais, lança mão da identificação com figuras de poder que estimulam o ódio, via excitação, para dar conta da sexualidade que o tornaria vulnerável a sentimentos de exclusão.

Usando estas duas possibilidades, reflito sobre o fenômeno social e político contemporâneo de alastramento do ódio, como a busca de um estado mental grupal de cisão radical, em que só haveria duas posições frente ao outro: um vence, o outro é vencido. Tal configuração é estimulada pelo sistema capitalista neoliberal que advoga a lei exclusiva do mercado, o que resulta, ao final, que o ganho de um se baseia na perda do outro.

\footnotetext{
${ }^{1}$ Este trabalho foi apresentado na mesa "Excitação do ódio: o massacre do outro" com Camila Salles Gonçalves no I Simpósio Bienal "O mesmo, o outro: Psicanálise em movimento" da Sociedade Brasileira de Psicanálise de São Paulo.

${ }^{2}$ Membro efetivo e Analista Didata da Sociedade Brasileira de Psicanálise de São Paulo, Doutora e Pós-Doutora em Psicologia pelo IPUSP, diretora do Instituto Durval Marcondes
} 


\section{A origem do ódio?}

Bia, 5 anos, é bastante pequena para a idade e tem duas irmãs já adolescentes; seus pais viajam com freqüência, tendo intensa vida social. Após duas semanas sem sessão (uma por viagem minha, outra dela), ela chega, como sempre, com a babá; está arrumada, pois vai a uma festa. Senta à minha frente e come uma banana, com deleite. “-Hoje não quero brincar...Estou com raiva de todo mundo lá dentro..." (apontando a caixa)

“-É que nós ficamos muito tempo sem nos vermos, não?"

Ela pega dois bebês e diz que a maior vai ter que emprestar a toalha para a menor. A maior reclama (eu faço este papel seguindo suas indicações); Bia é a mãe, e diz (com sotaque pronunciado, mimetizando o da própria mãe): “-Vai ter que emprestar, sim!” A filha faz um escândalo, ela diz que vai dar um castigo e coloca durex na boca da boneca: “-Para você não gritar mais!!!” Ainda usando durex, a amarra na cadeira (penso que agora a boneca não foge, não viaja).

Começa uma sessão de tortura ...Bia vai falando com a boneca, com voz e expressão sádicas: “-Você quer comidinha? Rárá! Vai ter veneno!” E derrama bolinhas de massa-veneno na boneca. Continua com um tom muito cruel: “-Ah! Você quer papá? Não vai ter! E seu cabelinho? Quer que eu penteie? Vou cortar!!!” E vai cortando o chumacinho de cabelo da boneca, aos poucos, uma verdadeira castração- imagino o horror de qualquer menina ao ter o cabelo cortado! Pega então uma bonequinha princesa e o boneco príncipe; este diz que vai matar a filha e o casal fica se beijando na frente da boneca amarrada...

Não é fácil assistir esta cena: nela, eu sou a boneca e ela é a mãe poderosa, mas ela também é a boneca: Bia invoca, exorciza e tenta desfazer a condição infantil. Esta, em sua fantasia cruel, se caracteriza por estar amarrada, amordaçada, vendo a cena primária, envenenada, castrada.

Será esta a origem do ódio? Steiner (2015), afirma: “O ódio do objeto real é...uma combinação de ataques invejosos a sua bondade e uma rebelião contra sua maldade" (p. 921). 
Com Bia, há nitidamente o ressentimento frente à situação infantil de dependência, que se fortalece nas experiências de separação. Ela se identifica com a mãe, cheia de crianças, que retém na ponta dos dedos o poder de dar amor (toalhas, comidas, carinho) e morte (castigos, veneno, castração). Eu é que fico horrorizada a viver/assistir a crueldade.

Por outro lado, como também lembra Steiner (2015): "Frequentemente, só depois que os ataques ocorreram é que a bondade pode ser reconhecida, e apenas então o amor e desejo de reparação podem ser liberados” (p. 921).

Ou seja, estes ataques dramatizados são também demonstração do potencial para a coexistência de ódio e amor, mantendo a ligação entre o sujeito e o objeto, o outro.

\section{O caso do menino e Hitler}

Mateus, 13 anos, teve dificuldades no desenvolvimento precoce que comprometeram sua sociabilidade e senso comum. Tinha muito interesse por armas e corporações policiais, expressando o desejo de pertencer a uma delas quando crescesse. Um dia, ele foi à sessão levando um Pixuleco. Eram os meses em que o processo de impeachment corria. Pedi (mal contendo a indignação), que deixasse o boneco na sala de espera...Algumas dias mais tarde, ele chegou querendo saber da Segunda Guerra Mundial e de Hitler, perguntando-me como era o hino dos nazistas. Também curiosa, cedi à tentação e fomos procurar na internet, achando o vídeo "In Feindesland" ("Em terra inimiga", ou "Teufelslied”, "Canção do diabo"), que trata da campanha da SS na União Soviética. A música e as cenas se alojaram na minha cabeça com uma estranha força, pois tudo que era proclamado e enaltecido no filme ia na contramão dos meus valores. Um misto de fascinação e terror era provocado em mim: fascinação pela "dança militar perfeita" e terror pelo que eu já sabia que estava incluído.

Naquela noite, ao deitar, em um estado hipnagógico, me veio uma imagem/sonho: em frente a mim, alguém puxava penas da boca, e acabava por arrancar um ganso inteiro de dentro de si...imagem que me trouxe um angustiado senso de estranhamento. Pensei nos passos de ganso das tropas da SS, perfeitamente sincrônicos, jovens rostos voltados de lado, onde deveria estar seu Führer e no poder mágico que este exercia sobre as multidões alemãs na época. 
Na sessão seguinte, meu paciente desaba no sofá e dorme. Após uns minutos, entre surpresa com aquela inédita ocorrência e na expectativa de entender melhor o que ocorria, eu o chamo, em tom baixo: “-Mateus!” Ele acorda e, sorrindo, me diz que estava sonhando que alguém o chamava. Digo que sim, ele acordou porque sonhou que eu queria que ele voltasse para mim, para ficarmos junto e conversarmos.

Percebo então que ele teve uma ereção, o que faz com que fique esfregando e alisando sua calça de moletom.

Mateus fala: “-Sabe que acho que o Hitler está solto por aí? Nunca acharam o corpo dele..."

Sem pensar muito, acrescento, lembrando do hino da SS, no qual o refrão é este: “-E o diabo diz: rá rá!”

Mateus pergunta: “-O diabo entrou na cabeça do Hitler?

Digo então que ele quis ir para dentro de si mesmo, no sono, porque aqui fora aconteciam umas coisas estranhas e diferentes com o corpo dele e ele tinha medo que existisse uma espécie de Hitler do diabo entre suas pernas. Ele ri, descontraído agora.

Vemos assim que Hitler e sua excitação militar contagiante vinham como um prenúncio da sexualidade que eclodia. Mateus evitou a catástrofe da sexualidade primeiro pelo nazismo, depois pelo sono, mas pôde voltar a ela no final, permitindo que tocássemos, ainda que brevemente, o teor de suas ansiedades.

Quero salientar neste fragmento a excitação que acaba contendo/cooptando a sexualidade, e com ela se confundindo, subvertendo sua função de ligar duas pessoas. Ao invés de ligação íntima, a excitação pode servir como estímulo à contaminação emocional, à idolatria e ao ódio como remédio contra a vulnerabilidade. Gera nas massas um sentimento de compartilhar, de estar irmanado e triunfante nessa experiência altamente carregada de emoção, como um rastilho de pólvora que se alastra com potencial de destruição multiplicado.

Refiro-me ao ambiente social/grupal de ódio que pode se estabelecer. Não foi à toa que trouxe o segundo exemplo, pois a ascensão do nacional-socialismo é exemplar e traz elementos importantes para nossa reflexão ao criar um mundo em que a ordem dos extremos se estabelece. É o mundo exclusivo da cisão, esquizoparanóide, onde há heróis de um lado e de outro, não diria demônios, pois estes têm poder, mas antes 
seres desprezíveis. Como os judeus se transformaram em sub-raça na propaganda nazista? Como se transforma em desprezível um líder popular, a ponto de se criar um Pixuleco? E como aquele ato, provavelmente baseado na ingenuidade de meu paciente, foi vivido por mim como provocação, impedindo-me de pensar analiticamente? Estando do outro lado, também entrei no estado reativo, não reflexivo.

\section{Como estimular o ódio nos grupos}

A propaganda maciça é uma arma eficaz para levar certo contingente de pessoas ao ponto desejado: a cisão e identificação com determinados "heróis" pode ser programada pelo poder (dos meios de comunicação, por exemplo), numa manobra para inundar e moldar grupos.

Além disto, há a facilitação específica da vida digital frente à disposição humana para o ódio: conforme alguns estudos (Vicario, Bessi, Zollo et al., 2016), os indivíduos acessam a rede não com o objetivo de aproveitarem a diversidade e conhecerem novas ideias, mas de afirmarem aquelas que já têm, tendendo a se agruparem em comunidades de seu interesse, em um fenômeno designado como "echo chamber".

Como psicanalistas, seria desejável irmos além do manifesto e tentarmos esclarecer o significado latente dos comportamentos. Segal nos alertava para o aspecto oculto nos debates e tendências políticas (Segal, 1987), e Rustin (2010) enfatiza como é fundamental reconhecer as fantasias inconscientes subjacentes a ambos os lados de um conflito político, o que deixa implícito que temos que também nos investigar.

Seria o atual estado de acirramento de ódio e polarização, particularmente entre esquerda e direita ${ }^{3}$, um conflito entre culpa e vergonha, como coloca Benjamin (2004), no qual a esquerda estaria lutando por se sentir culpada pelo tanto que tem [e do qual não quer abrir mão] e a direita pela vergonha pela fraqueza, dependência e vulnerabilidade humanas, adotando, portanto, a defesa da força, do ter e do poder?

\footnotetext{
${ }^{3}$ Uso aqui uma divisão muito simples: a esquerda se caracterizaria por lutar contra as desigualdades sociais, sendo que a direita consideraria as mesmas inevitáveis e naturais.
} 
Segundo a autora, a atitude moralista da esquerda, sem levar em conta o sentido latente da disputa (o terror paranóico da vulnerabilidade e da perda), poderia acirrar ainda mais a divisão, fazendo com que a direita identifique a esquerda ou como masoquistas e vitimizados (os intelectuais), ou como usurpadores, ladrões e corruptos. Se você sobe a um cargo de presidência sendo pobre, é porque roubou, não há outra saída; a tentativa de diminuição de desigualdade pode também equivaler a roubar concretamente. O outro é o inimigo que quer se apossar de suas coisas. Não é vizinho, é invasor.

É claro que ambos os lados são compostos de extratos distintos: a esquerda por trabalhadores e simpatizantes, e a direita por capitalistas e pelos que aspiram a sê-lo. Há, de fato, uma luta de classes, uma oposição entre movimentos sociais de reivindicação de direitos concretos, e capitalistas ou simpatizantes.

Assim, ainda que o ódio seja provocado, possa até ter sido orquestrado, ele também surge de uma contradição e de um conflito inerente ao sistema capitalista e à condição humana, seguindo depois um caminho próprio, que se mantém para ambas as partes e que vai na contramão da possibilidade de pensar.

Faço aqui uma analogia com as patologias autísticas, nas quais, por falhas multifatoriais no desenvolvimento, não se cria um espaço dialógico interno no qual self e outro possam coexistir e negociar, levando a uma incompatibilidade existencial: ou self massacraria o outro, ou o outro massacraria o self (Fonseca, 2006). O recurso da experiência sensorial e a excitação daí advinda tornam-se uma das bases da existência, em detrimento das emoções relacionais. Porém o que descrevemos aqui como a excitação do ódio é diversa: o outro é reconhecido como tal, mas teria que ser continuamente massacrado pelo self [grupal] como modo de manter uma rígida configuração vertical na qual só há vencidos ou vencedores, em que o triunfo é a emoção buscada e mantido à custa da excitação que substitui as nuanças e imprevisibilidade das emoções relacionais, e com elas, a percepção da impotência e da dependência.

O capitalismo neoliberal assume, como cerne de sua lógica, esta mesma configuração vertical, a da competição básica em que os "fortes" teriam sucesso e os outros seriam 
os fracos e perdedores. Há outras tendências que se opõem a isto, acreditando ser possível um estado de colaboração.

Como psicanalistas, sabemos que mesmo que apostemos na colaboração, isto não nos faz bons em essência, e que devemos ver além destas disposições. Mas, como dito acima, há entre esquerda e direita uma luta de classes real, em que o lucro de um é a pobreza do outro; em que a desobrigação do empregador é a instabilidade do empregado. Se o estado, como pais tendenciosos, só protege os filhos que têm sucesso, o ódio fratricida virá se juntar ao ódio como excitação, e o caos da guerra pode imperar.

Quero finalizar com um dilema: mesmo que nos proponhamos a pensar e investigar nossas razes latentes, ainda assim não precisamos abrir mão de participar, do direito de resistir e lutar por uma sociedade diferente, que não seja regida apenas pelas leis do mercado, o novo deus de nossa teocracia contemporânea.

\section{Referências}

Altman, N. Benjamin, J. Jacobs, T. Wachtel, P. (2004). Is Politics the Last Taboo in Psychoanalysis?. Psychoanal. Perspect., 2(1):5-36.

- $\quad$ Essig, T. (2017). How the Trump Campaign Built a Political Porn Site to Sell the Pleasures of Hate: What Do We Do Now?. Contemp. Psychoanal., 53(4):516-532.

- $\quad$ Fonseca, V.R. Bussab, V.S. (2006). Self, Other and Dialogical Space in Autistic Disorders. Int. J. Psycho-Anal., 87(2):439-455.

- Rustin, M. (2010). Looking for the Unexpected: Psychoanalytic Understanding and Politics. Brit. J. Psychother., 26(4):472-479.

- Segal, H. (1987). Silence is the Real Crime. Int. R. Psycho-Anal., 14:312.

- Vicario, M., Bessi, A., Zollo, F. et al (2016). The spreading of misinformation online. PNAS ("Proceedings of the National Academy of Science") 113 (3) 554-559; https://doi.org/10.1073/pnas.1517441113 